\title{
RNA-seq analysis of virR and revR mutants of Clostridium perfringens
}

\author{
Lee-Yean Low ${ }^{1}$, Paul F. Harrison ${ }^{2}$, Ya-Hsun Lin ${ }^{1}$, John D. Boyce', Julian I. Rood ${ }^{1 \dagger}$ and Jackie K. Cheung ${ }^{1 *}$
}

\begin{abstract}
Background: Clostridium perfringens causes toxin-mediated diseases, including gas gangrene (clostridial myonecrosis) and food poisoning in humans. The production of the toxins implicated in gas gangrene, a-toxin and perfringolysin $\mathrm{O}$, is regulated by the VirSR two-component regulatory system. In addition, RevR, an orphan response regulator, has been shown to affect virulence in the mouse myonecrosis model. RevR positively regulates the expression of genes that encode hydrolytic enzymes, including hyaluronidases and sialidases.

Results: To further characterize the VirSR and RevR regulatory networks, comparative transcriptomic analysis was carried out with strand-specific RNA-seq on C. perfringens strain JIR325 and its isogenic virR and revR regulatory mutants. Using the edgeR analysis package, 206 genes in the virR mutant and 67 genes in the revR mutant were found to be differentially expressed. Comparative analysis revealed that VirR acts as a global negative regulator, whilst RevR acts as a global positive regulator. Therefore, about $95 \%$ of the differentially expressed genes were up-regulated in the virR mutant, whereas $81 \%$ of the differentially expressed genes were down-regulated in the revR mutant. Importantly, we identified 23 genes that were regulated by both VirR and RevR, 18 of these genes, which included the sporulation-specific spoIVA, sigG and sigF genes, were regulated positively and negatively by RevR and VirR, respectively. Furthermore, analysis of the mapped RNA-seq reads visualized as depth of coverage plots showed that there were 93 previously unannotated transcripts in intergenic regions. These transcripts potentially encode small RNA molecules.
\end{abstract}

Conclusion: In conclusion, using strand-specific RNA-seq analysis, this study has identified differentially expressed chromosomal and pCP13 native plasmid-encoded genes, antisense transcripts, and transcripts within intergenic regions that are controlled by the VirSR or RevR regulatory systems.

Keywords: RNA-seq, Gene transcription, Reciprocal gene expression, C. perfringens

\section{Background}

Clostridium perfringens is a Gram-positive, sporeforming anaerobic rod that is ubiquitous in the environment and is found in the gastrointestinal tract of humans and animals $[1,2]$. It causes a wide range of diseases in humans, such as clostridial myonecrosis or gas gangrene, food poisoning and necrotizing enterocolitis. In animals it causes lamb dysentery, ovine enterotoxemia and avian necrotic enteritis [1,3]. These diseases are primarily toxin-mediated and the toxin

\footnotetext{
* Correspondence: jackie.k.cheung@monash.edu

Julian I. Rood and Jackie K. Cheung as joint senior authors.

${ }^{\dagger}$ Equal contributors

${ }^{1}$ Infection and Immunity Program, Biomedicine Discovery Institute and Department of Microbiology, Monash University, Clayton 3800, Australia Full list of author information is available at the end of the article
}

genes can be either chromosomal or plasmid-encoded [4]. For example, in gas gangrene strains, the major toxin genes $p l c$ ( $\alpha$-toxin) and $p f o A$ (perfringolysin $\mathrm{O}$ or $\theta$-toxin) are chromosomally encoded, whilst in animal isolates, the $\beta$-toxin, $\varepsilon$-toxin, $\mathrm{l}$-toxin and NetB toxin genes are present on plasmids [4].

Of the 20 known toxins or hydrolytic enzymes produced by $C$. perfringens $[2,5,6], \alpha$-toxin and perfringolysin $\mathrm{O}$ are the primary virulence factors involved in the pathogenesis of gas gangrene [7, 8]. Extracellular hydrolytic enzymes such as sialidases (NanI and NanJ) have also been implicated in disease and postulated to modulate the effect of $\alpha$-toxin [9]. Furthermore, these enzymes have been proposed to act as spreading factors that destroy the physical properties of tissue matrices and intercellular spaces, thereby aiding in the spread of 
bacteria within the host [10]. However, mutations in the nanI and nanJ genes did not affect virulence in the mouse myonecrosis model [11].

The production of $\alpha$-toxin, perfringolysin $\mathrm{O}$ and some extracellular enzymes is regulated by the VirSR twocomponent system $[12,13]$, small regulatory RNA molecules (sRNAs) [13, 14], and the RevR orphan response regulator [15]. The VirSR regulatory system is a typical two-component signal transduction system consisting of the membrane-bound sensor histidine kinase, VirS, and the cytoplasmic response regulator, VirR $[12,16]$. In response to an appropriate quorum sensing signal, which has been proposed to be an Agr-like autoinducing peptide [17, 18], VirS is autophosphorylated. The phosphoryl group is then transferred to a conserved aspartate residue (D57) in VirR. Once phosphorylated, VirR directly stimulates or represses target gene expression by binding to two imperfect direct repeats, called VirR boxes, which are located upstream of the target genes $[19,20]$. Genes that encode perfringolysin $\mathrm{O}(p f o A), \alpha-$ clostripain (ccp) and three sRNAs (vrr, virT, and virU) are the only genes known to have upstream VirR boxes in C. perfringens strain 13 [14, 20, 21]. Of the sRNAs, the best studied is VR-RNA (encoded by vrr), which acts as a secondary regulatory molecule that controls the expression of 147 genes, including chromosomally encoded genes such as plc and colA (encoding k-toxin), as well as the pCP13 encoded genes, $c p b 2$ (encoding $\beta 2$-toxin) and $c n a B$ (encoding a putative collagen adhesion) $[22,23]$. By contrast, VirT regulates the expression of $p f o A$ and $c c p$ [14], while VirU controls the expression of $p f o A, c c p$, vrr and virT [21].

RevR has been shown to modulate virulence in a VirSR-independent manner since the expression of the VirSR-regulated virulence-associated genes, $p l c$ and $p f o A$, is unchanged in a revR mutant [15]. Sequence alignment and structure prediction of RevR has shown that it is similar to the response regulators $\mathrm{PhoB}$ from Escherichia coli and YycF from Bacillus subtilis [15]. Since a potential winged-helix-turn helix DNA binding domain was present within the C-terminal domain of RevR, it was proposed that RevR controls its regulon by binding to a DNA target [15]. Although the mechanism of action of RevR is still unclear, microarray analysis has revealed that RevR regulates many genes including those encoding hydrolytic enzymes (nagL, nagH, nanI, nanJ and $c c p$ ) and some sporulation genes. Importantly, a revR mutant was attenuated for virulence in the mouse myonecrosis model when compared to its wild-type parent [15].

In this study, to further characterize the VirSR and RevR regulatory systems, we carried out RNA-seq analysis of the $C$. perfringens strain JIR325, a derivative of strain 13, and its isogenic virR and revR regulatory mutants. Comparative strand-specific RNA-seq was used to identify all genes, sRNA and antisense transcripts that may be part of the VirSR or RevR regulons. These transcriptome analyses revealed that VirR is a global repressor and that RevR is a global activator. Importantly, VirR and RevR regulated several common genes, but in a reciprocal manner.

\section{Methods}

\section{Bacterial strains and culture conditions}

C. perfringens strain JIR325, a rifampicin and nalidixic acid resistant derivative of strain 13 [12], and its derivatives,

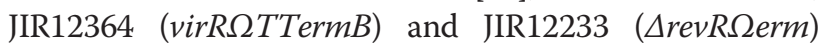
[15], were used in this study. The virR mutant was constructed by Targetron mutagenesis using the virR Targetron plasmid, pJIR3608, as outlined previously [24]. Potential mutants that had been cured of pJIR3608, but retained the Targetron insertion, were selected and analyzed by PCR and Southern blot hybridization as described previously [24]. One of these confirmed virR mutants, JIR12364, was selected for further analysis.

C. perfringens broth cultures were grown overnight at $37{ }^{\circ} \mathrm{C}$ in fluid thioglycolate (FTG) medium or in TPG broth medium (5\% (w/v) tryptone, $0.5 \%(\mathrm{w} / \mathrm{v})$ protease peptone and $0.1 \%(\mathrm{w} / \mathrm{v})$ sodium thioglycolate) with glucose added to a final concentration of $0.38 \%(w / v)$ after sterilization. Agar cultures of C. perfringens were grown on nutrient agar (NA) (Oxoid or Difco, BD) supplemented with rifampicin $(10 \mu \mathrm{g} / \mathrm{ml})$, nalidixic acid $(10 \mu \mathrm{g} / \mathrm{ml})$ or erythromycin $(50 \mu \mathrm{g} / \mathrm{ml})$ under anaerobic conditions $\left(10 \%(\mathrm{v} / \mathrm{v}) \mathrm{H}_{2}, 10 \%(\mathrm{v} / \mathrm{v}) \mathrm{CO}_{2}\right.$ and $80 \%(\mathrm{v} / \mathrm{v})$ $\mathrm{N}_{2}$ ). Growth of these strains was determined by measuring the optical density (OD) at $600 \mathrm{~nm}$ using a WPA Biowave CO8000 cell density meter.

\section{Isolation of total RNA}

C. perfringens strains were grown at $37^{\circ} \mathrm{C}$ in TPG broth with an initial $\mathrm{OD}_{600}$ of 0.05 and cells were harvested by centrifugation at $8000 \mathrm{~g}$ for $10 \mathrm{~min}$ at room temperature, when the culture had reached late logarithmic phase $\left(5 \mathrm{~h} ; \mathrm{OD}_{600}\right.$ of $\left.1.8-2.0\right)$. The harvested cells were resuspended and incubated in lysis buffer $(10 \mathrm{mM}$ Tris-HCI $\mathrm{pH} 7.5,0.4 \mathrm{M}$ sucrose, $5 \mathrm{mg} / \mathrm{ml}$ lysozyme) at $37{ }^{\circ} \mathrm{C}$ for $30 \mathrm{~min}$. Following centrifugation at 16, $060 \mathrm{~g}$ for $10 \mathrm{~min}$, the supernatant was discarded and total RNA was isolated from the cells using TRIzol $^{\circ}$ reagent (Invitrogen) as previously described [15]. To remove contaminating DNA, the RNA was treated with $4 \mathrm{U}$ of TURBO DNase (Ambion) at $37^{\circ} \mathrm{C}$ for 90 min according to the manufacturer's instructions. To test for DNA contamination, the RNA was used as a template for PCR without reverse transcription using oligonucleotide primers for the housekeeping gene, rpoA (Additional file 1: Table S1). The PCR cycling conditions were as follows: $95{ }^{\circ} \mathrm{C}$ for 
$5 \mathrm{~min}$, followed by 30 cycles of $95^{\circ} \mathrm{C}$ for $1 \mathrm{~min}, 55^{\circ} \mathrm{C}$ for $1 \mathrm{~min}$, and $72{ }^{\circ} \mathrm{C}$ for $1 \mathrm{~min}$. RNA quality was also validated by use of a Nanodrop spectrophotometer (Thermo Fisher) and only RNA with an absorbance at 260/280 nm ratio of > 1.9-2.1 was used for cDNA synthesis.

\section{PCR, reverse-transcription-PCR (RT-PCR) and quantitative real-time PCR (QRT-PCR)}

All primers used in PCR, RT-PCR and QRT-PCR are listed in Additional file 1: Table S1. Standard PCR reactions were performed with Taq DNA polymerase (New England Biolabs). PCR cycling conditions were as shown earlier.

To examine gene expression and to validate RNA-seq data by QRT-PCR, $2 \mu \mathrm{g}$ of total RNA was used for first strand cDNA synthesis using random hexamers (Promega) and AMV-reverse transcriptase (Promega). The negative control samples were prepared by replacing AMV-reverse transcriptase with nuclease-free water and were labeled as NRT (no reverse transcriptase). The reverse-transcription reaction was incubated for $1 \mathrm{~h}$ at $42{ }^{\circ} \mathrm{C}$, followed by $10 \mathrm{~min}$ at $90{ }^{\circ} \mathrm{C}$ and $5 \mathrm{~min}$ on ice.

For QRT-PCR, each $25 \mu \mathrm{l}$ reaction contained $12.5 \mu \mathrm{l}$ of SYBR Green mastermix (Applied Biosystems), $1 \mu \mathrm{l}$ of forward and reverse primers (Additional file 1: Table S1) at a final concentration of $5 \mu \mathrm{M}, 1 \mu \mathrm{l}$ of cDNA, and the appropriate amount of nuclease-free water. A standard curve for each gene was generated from genomic DNA of JIR325. PCR conditions were as follows: initial denaturation at $95{ }^{\circ} \mathrm{C}$ for $15 \mathrm{~min}, 40$ cycles of $95{ }^{\circ} \mathrm{C}$ for $20 \mathrm{~s}, 50{ }^{\circ} \mathrm{C}$ for $30 \mathrm{~s}$ and $68^{\circ}$ for $20 \mathrm{~s}$. Reactions were confirmed as being the result of a single product by melting curve analysis. All QRT-PCRs were completed using the Mastercycler ep Realplex real time PCR system (Eppendorf) and were carried out on three independent biological replicates. The expression of each gene was normalized against the expression of the housekeeping gene, $\operatorname{rpo} A$, from the same biological replicate, before comparative analysis.

\section{RNA-seq library preparation and RNA-seq analysis}

Strand specific RNA-seq was carried out as before [25]. Briefly, for first strand synthesis (FSS), a $100 \mu$ l reaction that contained $8 \mu \mathrm{g}$ of total RNA and $15 \mu \mathrm{g}$ of random hexamers (Promega) was incubated at $65^{\circ} \mathrm{C}$ for $5 \mathrm{~min}$ and placed on ice for $5 \mathrm{~min}$. The reaction was then combined with $20 \mu \mathrm{l}$ of $5 \mathrm{X}$ first strand buffer (Invitrogen), $10 \mu \mathrm{l}$ of $100 \mathrm{mM}$ of dithiothreitol (DTT) (Invitrogen), $5 \mu \mathrm{l}$ of $10 \mathrm{mM}$ of deoxynucleotide (dNTP) mix (Promega) and $2.5 \mu \mathrm{l}$ of $40 \mathrm{U} / \mu \mathrm{l}$ RNasin (Promega) and incubated at $25{ }^{\circ} \mathrm{C}$ for $2 \mathrm{~min}$. Subsequently, $5 \mu \mathrm{l}$ of 200 $\mathrm{U} / \mu \mathrm{l}$ SuperScript III was added to the reaction and incubated under the following conditions: $25{ }^{\circ} \mathrm{C}$ for $10 \mathrm{~min}, 42{ }^{\circ} \mathrm{C}$ for $50 \mathrm{~min}$ and $70{ }^{\circ} \mathrm{C}$ for $15 \mathrm{~min}$. To remove excess dNTPs the FSS reaction was purified with a G-50 gel filtration spin column (GE Healthcare), according to the manufacturer's instructions. Second strand synthesis was carried out as previously described [25], The resultant cDNA samples were used to construct cDNA libraries, where end-repair, A-tailing, ligation of adapter primers, size selection and pre-amplification were carried out with the Truseq RNA sample preparation kit version 1 (Illumina) as per the manufacturer's instructions. The cDNA libraries were then sequenced as 100-mers using an Illumina Solexa GAIIx Sequencer by Micromon at Monash University. For each strain, two independent biological replicates were sequenced.

\section{RNA-seq data analysis}

To analyze the RNA-seq data, the read pairs firstly were clipped of low quality regions and adaptor sequences, then aligned to the reference genome of $C$. perfringens strain 13 (GeneBank accession: NC_003366 and NC_003042) using SHRiMP alignment software (http://compbio.cs.toronto.edu/shrimp/). If a sequence read aligned to multiple locations on the genome, all alignments were kept for downstream statistical analysis and were referred to as a multi-hit read. The total number of aligned reads at each genomic position was counted using the Nesoni software package (http://www.vicbioinformatics.com/software.nesoni.shtml), a high-throughput sequencing data analysis toolset used to generate coverage depth plots, which can be visualized in the Artemis genome browser [26]. The mapped transcriptome data were then viewed, in a strand-specific manner, as a graph relative to the genome annotation.

Before analyzing the data, scatter plots of the expression levels of all genes measured by read counts were generated using Microsoft Excel to show the correlation and reproducibility between the biological replicates for each strain. Spearman's rho correlation coefficient between two replicates was then calculated using $\mathrm{R}$ code [27, 28]. Transcriptomic analysis was carried out using the Bioconductor edge $\mathrm{R}$ analysis package [27], which uses a generalized linear model with a logarithmic link function and a negative binomial error distribution in the analysis. The dispersion parameter of the negative-binomial model was estimated per gene, and moderated with a global model of dispersion as a smoothly varying function of overall abundance (the "trend" option in edgeR). To minimize false positive results, a stringent cutoff of False Discovery Rate (FDR) $<0.01$ and $\log _{2}$ foldchange $>1$ was applied when identifying differentially expressed genes of the wild type compared to the mutant strains (Additional file 2: Table S2 \& Additional file 3: Table S3). 
With the Bioconductor "goseq" package [29], the differentially expressed gene lists (FDR $<0.01 ; \log _{2}$ fold-change $>1$ ) of the virR and revR mutants were mapped to known pathways at Kyoto Encyclopedia of Genes and Genomes (KEGG) and Gene Ontology (GO) [29] so that over-represented categories in the gene lists could be identified. Finally, to determine genes that were regulated by both VirR and RevR, the differentially expressed gene lists were analyzed in the Vennt program (http://www.vicbioinformatics.com/ software.vennt.shtml). Vennt generates dynamic Venn diagrams from differential expressed gene lists, which enables the identification of overlapping genes in the lists.

\section{RNA-seq data accession number}

The gene expression data have been deposited in the NCBI Gene Expression Omnibus (GEO) database with the GEO series accession number GSE72137.

\section{Identification of the potential sRNAs}

Many sRNA molecules are found within intergenic regions of bacterial genomes [30, 31]. Therefore, using the depth of coverage plot generated from the wild-type transcriptomic data, active transcription with a minimum length of 30 nucleotides and more than 10 reads within intergenic regions was recorded. A total of 93 previously unannotated transcripts were identified. These putative sRNAs were designated as SR1 to SR93 (Small $\underline{R} N A)$. These potential sRNAs included intergenic non-coding RNAs as well as 5'untranslated regions (UTRs), such as potential riboswitches, and 3' UTRs.

\section{Northern blotting analysis}

For Northern blot analysis, total RNA was isolated at hourly intervals ( 1 to $5 \mathrm{~h}$ ) from wild-type cells cultured in TPG broth at $37^{\circ} \mathrm{C}$. Hybridization probes of the selected sRNAs were generated using the appropriate primers (Additional file 1: Table S1). A total of $10 \mu \mathrm{g}$ of RNA from each time point was resolved by $1.5 \%(\mathrm{w} / \mathrm{v})$ agarose gel electrophoresis, transferred onto a nylon membrane and hybridized with specific probes. Northern blotting was carried out as previously described, with some modifications [32, 33]. DNA probes were generated by PCR using the genomic DNA of the wild type as a template and were labeled by use of the AlkPhos-direct kit (GE Healthcare Life Sciences). Primers used for probe generation are listed in Additional file 1: Table S1. Signals were detected using CDP-Star ${ }^{\circ}$ chemiluminescence (Roche). The autoradiograms were developed using a BAS 2000 Bio-Imaging Analyzer (Fuji Photo Film Co., Ltd., Kanagawa, Japan). All Northern blot analyses were performed at least twice using independently derived RNA preparations to confirm the reproducibility of the results.

\section{Results}

VirR acts as a global negative regulator, whilst RevR acts as a global positive regulator

To further characterize the VirSR and RevR virulencerelated regulatory systems, we carried out strand-specific RNA-seq analysis on the wild-type strain JIR325 and its respective virR and revR mutants, JIR12364 and JIR12233. RNA from each strain was extracted from cells cultured in TPG broth for $5 \mathrm{~h}$, which corresponded to late logarithmic growth phase. Two independent biological replicates were sequenced for each strain. Approximately $90 \%$ of the reads were retained after quality and adapter clipping, and of these reads, $97 \%$ aligned to the strain 13 reference genome (wild type, ca. $9.3 \mathrm{M}$ read-pairs per replicate; virR mutant, ca. $11.2 \mathrm{M}$ read-pairs per replicate and $\operatorname{revR} \mathrm{mu}-$ tant, ca. $12.7 \mathrm{M}$ read-pairs per replicate). Note that because the rRNA was not depleted from the total RNA samples, many of these reads (92\%) were derived from the rRNA transcripts. Scatter plots were generated to demonstrate the reproducibility between the two biological replicates (Additional file 4: Figure S1A-C). With Spearman's rho correlation coefficients of greater than 0.928 , the data were deemed to be highly reproducible.

In the virR mutant, 206 chromosomally encoded genes were found to be differentially expressed compared to the wild type (Additional file 2: Table S2). Of these genes, $95 \%$ (195) were expressed at a higher level in the virR mutant compared to the wild type, with only $5 \%$ (11) having lower expression in the virR mutant (Fig. 1a). These results indicate that VirR acts primarily as a global transcriptional repressor. Nevertheless, VirR positively regulated the expression of 11 chromosomally encoded genes (Additional file 2: Table S2), including five genes (ccp, virT, virU, vrr and $p f o A)$ with upstream VirR boxes [20]. The six remaining genes, encoding transporter proteins (encoded by $p s t C$, fruA, nirC and cpe0947), a phosphoribosymaninomidazole carboxylase catalytic subunit (purE) and a hypothetical protein (cpe0844) (Additional file 2: Table S2), did not contain upstream VirR boxes.

By contrast, in the revR mutant, 67 chromosomally encoded genes were found to be differentially expressed (Additional file 3: Table S3). Of these genes, $81 \%$ (54) were expressed at a lower level in the revR mutant compared to the wild type, providing evidence that RevR acts primarily as a global transcriptional activator (Fig. 1b). The RevR regulon included genes encoding hyaluronidases (nagH, nagI, nagJ, nagL), a sialidase (nanJ), a protease $(\operatorname{csp} B)$ and a transcriptional repressor (ctsR) (Additional file 3: Table S3). Furthermore, consistent with our previous microarray study [15], RevR enhanced the expression of genes encoding several hydrolytic enzymes including $\mathrm{NagH}, \mathrm{NagL}$ and NanJ (Additional file 3: Table S3). The revR and virR genes were expressed at 

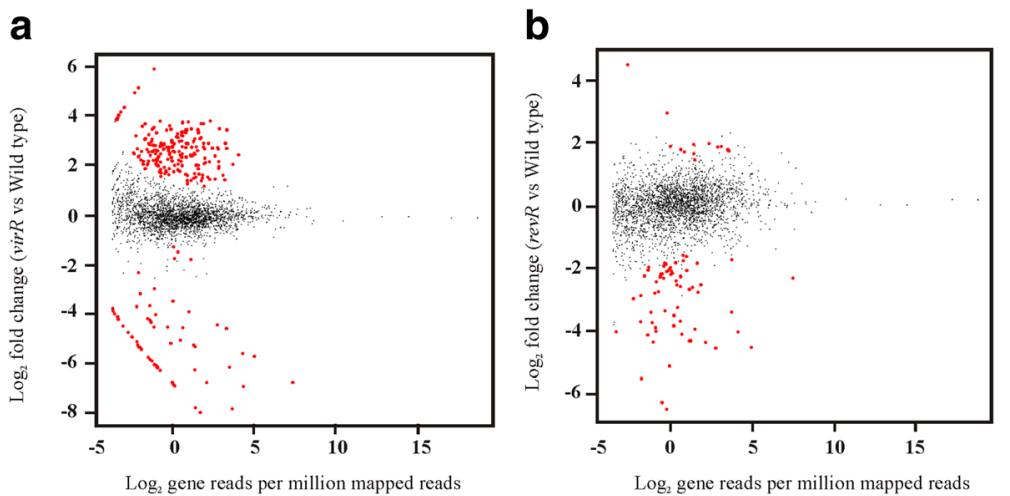

Fig. 1 Relative gene expression of the virR and revR mutants compared to the wild type. Strand-specific RNA-seq libraries of the wild-type strain JIR325 and its virR and revR mutants were generated from RNA extracted from each strain. Comparative transcriptomic analysis was carried out and differentially expressed genes in the $\mathbf{a}$ virR and $\mathbf{b}$ revR mutants were identified using the "DESeq" R package. In the MA (log ratios versus mean average) plots that are shown, each point represents a gene. Red dots represent genes with a significant change in expression with a cutoff of FDR $>0.01$ and an absolute $\log _{2}$ fold change $>1$. Black dots denote genes with a fold change that is not within the range of the set cutoff. The " $Y$ " axis represents the $\log _{2}$ fold change compared to the wild type and the " $X$ " axis is the average $\log _{2}$ normalized counts in two independent biological replicates

levels similar to wild type in the virR and revR mutants, respectively. In the revR mutant, the $\log _{2}$ fold change of virR was 0.425 with an FDR of 0.711, while in the virR mutant, the $\log 2$ fold change of $\operatorname{rev} R$ was 0.0913 with an FDR or 0.9767. The FDRs of both genes were notably higher than the 0.01 threshold, indicating that they were not significantly different from the levels in the wild type. These results suggest that these genes are expressed independently.

QRT-PCR was employed to validate the expression of selected VirR-regulated genes (Fig. 2a). To encompass a range of expression changes, an up-regulated gene $(\operatorname{csp} B)$ and two down-regulated genes ( $p f o A$ and $c c p)$ were selected for validation. In agreement with the RNA-seq data, QRT-PCR confirmed that the expression of the $p f o A$ and $c c p$ genes was reduced and that expression of $\operatorname{csp} B$ was increased in the virR mutant. The expression of the plc gene was also of interest, as it encodes the major toxin involved in gas gangrene [7]. With the stringent criteria used here $(F D R<0.01$ and fold change $>2$-fold), the expression of plc was not deemed to be changed. However, previous work has shown that $\alpha$-toxin production is reduced in a virR mutant [12]. Closer inspection of the RNA-seq data showed that the plc gene did show weakly reduced expression (1.8-fold reduced expression; FDR $=0.04)$. Therefore, QRT-PCR was employed to further examine plc gene expression. The QRT-PCR confirmed that plc was downregulated in the virR mutant compared to the wild type (Fig. 2a; 2.2-fold change, $P<0.05$ ).

For validation of the revR RNA-seq expression data, QRT-PCR was performed on the $p f o A, p l c$, nirC and
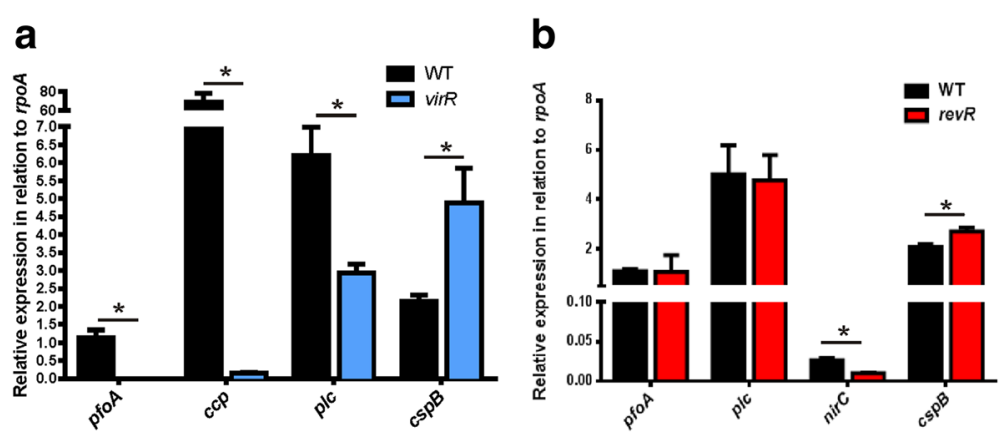

Fig. 2 QRT-PCR validation of selected genes in the virR and revR mutants. RNA was extracted from cells grown in TPG broth for 5 h, which corresponded to the late logarithmic growth phase. RNA was converted to cDNA using reverse transcriptase, and was subsequently used as the template in QRT-PCR, which was performed to validate the relative expression of the $p f O A, c c p, p / c$, and $c s p B$ genes in the virR mutant (a) and the expression of the $p f o A, p / c$, nirC and $\operatorname{csp} B$ genes in the revR mutant (b). Expression levels are shown relative to the expression of the housekeeping gene, $r p \circ A$, and are the average of at least three independent biological replicates $(n \geq 3$, mean \pm SEM). The asterisk $(*)$ denotes a statistically significant difference $(p \leq 0.05)$ as calculated with the student's unpaired $t$-test 
$\operatorname{csp} B$ genes (Fig. 2b). These genes were selected as they represented genes whose expressions were either unchanged $(p f o A, p l c)$, down-regulated $(n i r C)$ or upregulated $(\operatorname{csp} B)$ in the revR mutant. The QRT-PCR results (Fig. 2b) were in agreement with, and thereby validated, the RNA-seq data.

\section{Functional classification of differentially expressed genes}

To allow functional analysis of the differentially expressed genes, they were classified into specific Gene Ontology (GO) groups [34] and pathways using the Kyoto Encyclopedia of Genes and Genomes (KEGG) [35]. These analyses indicated that many genes encoding components involved in sporulation and developmental processes were differentially expressed in the virR mutant (Fig. 3a), while genes encoding proteins associated with metabolite transport systems and membrane integrity were differentially expressed in the revR mutant (Fig. 3b).

Genes encoding proteins within the hyaluronidase/collagenase/cell adhesion functional category were significantly over-represented in the differentially expressed genes sets for both the virR and revR mutants (Fig. 3). In the virR mutant, the genes encoding NagH, NanJ, CPE0818 (Endo-beta-N-acetylglucosaminidase), CPE0866 (alpha $\mathrm{N}$-acetylglucosaminidase), NagJ, NagL, a sialidaselike-protein (CPE1264), and a hypothetical protein (CPE1364) showed increased expression, whereas in the revR mutant genes encoding $\mathrm{NagH}$, NanJ, NagJ, NagL, CPE0866, NagI and the hypothetical protein (CPE1876) showed reduced expression.
Several genes are regulated by both VirR and RevR To reveal the distinctive roles of VirR and RevR, we identified genes that were regulated by only one or both of these response regulators. More genes were regulated solely by VirR (183) than by RevR (44) (Fig. 4). Genes encoding ferredoxin (CPE2511 and CPE1065), PTS system proteins (CPE2629, CPE2631 and CPE2632) and more than 30 sporulation-related proteins are examples of the genes that were regulated only by VirR (Additional file 2: Table S2). Genes encoding putative $\mathrm{ABC}$ transporters (CPE2031, CPE2081, CPE2082, and CPE0576-0578), a transcriptional repressor (CtsR), and a signal peptidase type I (CPE2295) were among the genes that were regulated only by RevR (Additional file 3: Table S3).

By contrast, 23 chromosomal genes were regulated by both VirR and RevR (Table 1). Eighteen of these genes were expressed at higher levels in the virR mutant and at lower levels in the revR mutant compared to the wild type (Table 1) (Fig. 4). Functional characterization of these 18 genes showed that they encoded proteins that were clustered into a few functional groups, namely proteins with fibronectin type III domains (CPE0818 and CPE1875), several extracellular hydrolytic enzymes (NagH, NanJ, NagJ and NagL), sporulation-associated proteins (SigF, FtsN, SpoIIIAG, SigG and SpoIVA), galactoside transporters $(\mathrm{MglB}, \mathrm{MglA}$ and $\mathrm{MglC})$ and three hypothetical proteins (Table 1). PSI-BLAST searches and InterProScan analysis of the hypothetical proteins showed that CPE2262 and CPE0554 contained a metalloprotease domain and that CPE2261 was a putative extracellular solute binding protein that may function in the initiation of sensory transduction pathways.

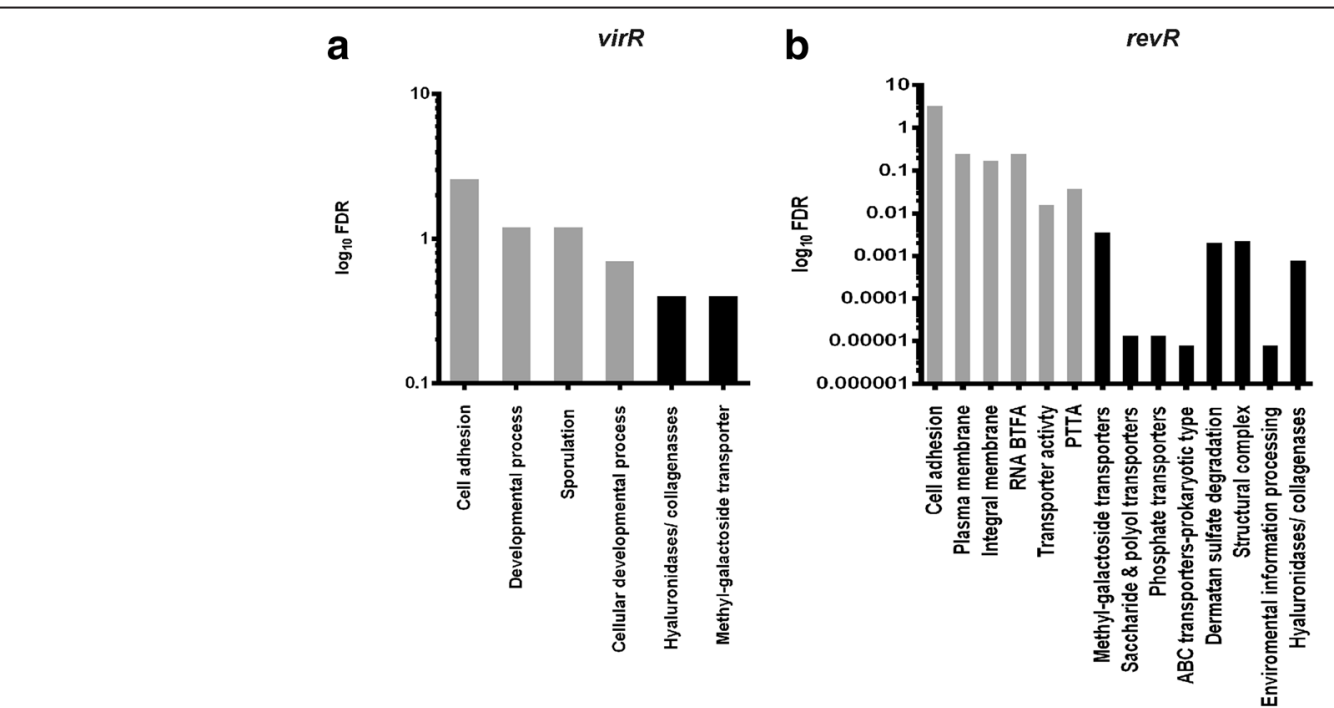

Fig. 3 Gene Ontology (GO) and KEGG enrichment analysis. Bar charts denote the $\log _{10}$ FDR (False Discovery Rate) of over-represented GO (grey) and KEGG (black) categories in the $\mathbf{a}$ virR and $\mathbf{b}$ revR mutants as identified by the "Goseq" Bioconductor package. Abbreviations: RNA BTFA: RNA polymerase binding transcription factor activity; PTTA: phosphate transmembrane transporter activity 


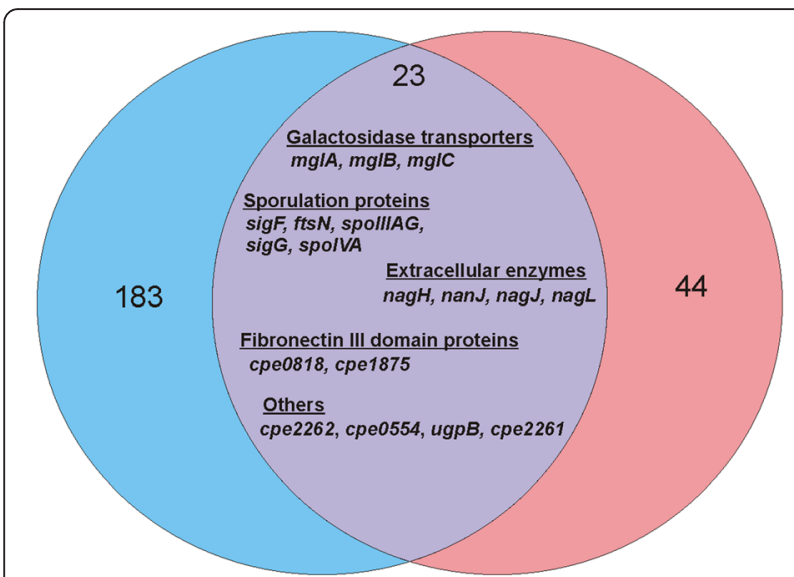

Fig. 4 Genes that were regulated by both VirR and RevR. The Venn diagram generated with Vennt software represents the number of genes that were regulated by VirR (183; blue), RevR (44; pink) or both (23; purple). The 18 genes that were controlled by both regulators are indicated. The five genes that were regulated in a similar manner by VirR and RevR are not listed here
Four genes were regulated by both VirR and RevR in the same manner: $\operatorname{csp} B, \operatorname{rubY}$, fruA and $p s t C$ (Table 1). The $\operatorname{csp} B$ and $r u b Y$ genes were expressed at higher levels in both mutants, whereas the fruA and pstC genes were expressed at lower levels compared to the wild type (Table 1). These results suggested that VirR and RevR have both common and distinct functional roles in C. perfringens.

\section{VirR and RevR regulate genes located on the native plasmid, pCP13}

Strains 13 and its derivatives harbor the $54.3 \mathrm{~kb}$ plasmid pCP13, which carries a $\beta 2$-toxin gene, $c p b 2$ [36]. The VirSR regulatory system, via its secondary regulator, VRRNA, is known to regulate the expression of two pCP13-encoded genes, $c p b 2$ and $c n a B$ [37]. To further explore the role of VirR and RevR in the regulation of plasmid genes, the RNA-seq reads were also mapped to the 63 genes on $\mathrm{pCP} 13$.

The transcription of 47 of the $63 \mathrm{pCP} 13$ genes was altered in the virR mutant (Additional file 5: Table S4). By contrast, only seven plasmid-encoded genes, including

Table 1 Genes regulated by both VirR and RevR

\begin{tabular}{|c|c|c|c|c|c|}
\hline Functional Group & Locus & Gene Name & Putative Product & $\begin{array}{l}\log _{2} \text { fold change: } \\
\text { virR vs } W^{a}\end{array}$ & $\begin{array}{l}\log _{2} \text { fold change: } \\
\text { revR vs } W^{a}\end{array}$ \\
\hline \multirow[t]{4}{*}{ Extracellular enzyme } & сре0191 & nagH & hyaluronidase & 2.07 & -1.77 \\
\hline & сре0553 & nan & sialidase & 2.15 & -3.41 \\
\hline & cpe1234 & nagl & hyaluronidase & 1.90 & -2.10 \\
\hline & сре1523 & nagl & hyaluronidase & 1.44 & -2.07 \\
\hline \multirow[t]{5}{*}{ Sporulation proteins } & cpe2048 & sigF & sporulation sigma factor & 1.98 & -1.98 \\
\hline & cpe2146 & $f t s N$ & Sporulation/cell division protein & 1.56 & -2.09 \\
\hline & cpe1827 & spolllAG & sporulation protein AG & 3.02 & -4.03 \\
\hline & cpe1761 & $\operatorname{sig} G$ & sporulation sigma factor & 2.73 & -2.06 \\
\hline & cpe1753 & spolva & sporulation protein A & 2.73 & -2.44 \\
\hline \multirow[t]{3}{*}{ Galactoside transporters } & cpe1341 & $m g / B$ & galactoside $\mathrm{ABC}$ transporter & 2.42 & -3.90 \\
\hline & cpe1342 & mglA & galactoside $\mathrm{ABC}$ transporter & 2.70 & -3.71 \\
\hline & cpe1343 & $m g / C$ & galactoside $\mathrm{ABC}$ transporter & 2.69 & -4.36 \\
\hline \multirow[t]{2}{*}{ Fibronectin III domain proteins } & cpe1875 & cpe1875 & fibronectin/fucosidase & 1.40 & -1.84 \\
\hline & сре0818 & cpe0818 & endo-beta-N-acetylglucosaminidase & 1.63 & -2.26 \\
\hline \multirow[t]{4}{*}{ Hypothetical proteins } & cpe1257 & ugp $B$ & $A B C$ transporter substrate binding protein & 1.47 & -3.51 \\
\hline & cpe0554 & cpe0554 & camelysin-like protein & 2.45 & -3.25 \\
\hline & cpe2262 & cpe2262 & has a camelysin M73 family peptidase domain & 1.46 & -2.20 \\
\hline & cpe2261 & cpe2261 & hypothetical protein & 1.53 & -1.93 \\
\hline \multirow[t]{5}{*}{ Others $^{b}$} & cpe2562 & $\operatorname{csp} B$ & protease & 3.87 & 4.49 \\
\hline & cpe0855 & rubY & rubrerythrin & 1.42 & 1.66 \\
\hline & cpe0584 & fruA & PTS fructose transporter & -1.48 & -1.83 \\
\hline & cpe0638 & pstC & phosphate $A B C$ transporter permease & -1.27 & -6.50 \\
\hline & сре0094 & nirC & nitrite transporter & -1.75 & -5.13 \\
\hline
\end{tabular}

${ }^{a}$ As defined by FDR $<0.01 ; \log _{2}$ fold change $>1$

${ }^{\mathrm{b}}$ Genes that are regulated by VirR and RevR in the same manner 
$c n a B$, were found to be positively regulated by $\operatorname{RevR}$ (FDR <0.01, $\log _{2}$ fold change $>1$ ) (Additional file 6: Table S5). Analysis of the transcripts of all of the pCP13 genes by RNA-seq showed that the majority of the plasmid-encoded genes were expressed at lower levels in the virR and revR mutants, with the virR mutation having a greater effect on gene expression than the rev $R$ mutation (Fig. 5a). This observation was not due to pCP13 plasmid loss or instability, as the expression of a control gene, $p c p 43$, was validated using QRT-PCR and showed statistically similar expression in the wild type and mutant strains (Fig. 5b). QRT-PCR validation was also performed on the $c n a B$, pcp 17 and parB transcripts. The results correlated with the RNA-seq data, which showed decreased expression of the $c n a B$ gene in both mutants. The pcp17 and parB genes, were downregulated in the virR mutant, but their expression was not statistically different in the revR mutant (Fig. 5b).

\section{VirR and RevR regulate novel unannotated transcripts}

VirR regulates many genes by activating the transcription of sRNAs such as VR-RNA, VirT and VirU [13, 21]. To identify other potential sRNAs that may be regulated by VirR or RevR, the RNA-seq reads from each strain were mapped against the C. perfringens genome and analyzed by visual inspection in the Artemis genome viewer. A number of putative sRNAs were identified as strongly transcribed sections within intergenic regions. Importantly, the known VirR-regulated sRNAs, VRRNA, VirT and VirU, had low or no detectable expression in the virR mutant compared to the wild type (Fig. 6), confirming previous studies $[21,38]$ and validating this approach.

Detailed analysis of the genome-wide transcript data identified 93 transcripts that were longer than 30 nucleotides and located within intergenic regions. They were designated SR1 to SR93 (Additional file 7: Table S6). To confirm expression of these putative sRNAs, four transcripts were selected for validation by RT-PCR (Fig. 7) and one by Northern blot analysis (Fig. 8). These sRNAs were chosen based on their location near putative virulence-related genes, as sRNAs often regulate the expression of adjacent genes [39].

RT-PCR was carried out using RNA purified from $5 \mathrm{~h}$ cultures of the wild-type strain JIR325, the virR and revR mutant strains to replicate the conditions of the RNAseq analysis. The signals of the selected sRNAs on the wild-type depth of coverage plot were used to estimate the size of each sRNA. RT-dependent transcripts with the predicted sizes (Fig. 7a-e) were detected using specific primer pairs spanning SR14, SR16, SR42, SR50 and SR73 in both wild-type and mutant strains. The absence of products in the no RT reactions confirmed that the products were not derived from DNA contamination.

One of the four sRNAs, SR73, was also analyzed by Northern blotting (Fig. 8). Two transcripts, $0.85 \mathrm{~kb}$ and $0.25 \mathrm{~kb}$ in size, hybridized with the SR73-specific probe (Fig. 8). The faint $0.85 \mathrm{~kb}$ transcript was only observed in the RNA samples isolated during early growth phase (1 and $2 \mathrm{~h})$, indicating that SR73 $(0.25 \mathrm{~kb})$ was cotranscribed with the downstream gene, cpe2167 $(0.60 \mathrm{~kb})$ during this growth phase. The $0.25 \mathrm{~kb}$ band (SR73) was observed in increasing intensity in the RNA preparations from mid- and late-logarithmic phases (3, 4 and $5 \mathrm{~h}$ ). By contrast, the $0.85 \mathrm{~kb}$ band (SR73 and cpe2167) was detected only during the early logarithmic phase (1 and $2 \mathrm{~h}$ ). Bioinformatic analysis of the SR73 coding sequence indicated that SR73 was a putative Flavin mononucleotide (FMN) riboswitch. Its location upstream of cpe2167, in conjunction with the Northern blot results implied that SR73 could potentially repress the expression of cpe2167 through the
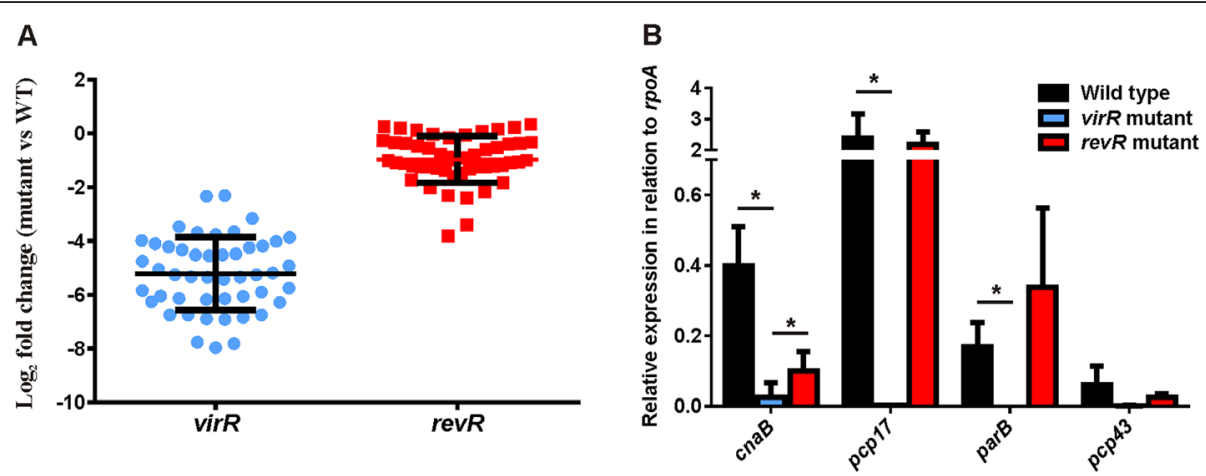

Fig. 5 Relative expression of pCP13 genes in the virR and revR mutants compared to the wild type. a The expression levels of all plasmid-encoded genes in the virR (blue) and revR (red) mutants. Note that no FDR and fold-change cutoff criteria were applied to the data represented here. $\mathbf{b}$ Real-time PCR was performed to validate differentially expressed PCP13 plasmid genes in the virR and revR mutants. Expression levels were relative to the expression of the housekeeping gene, $r p \circ A$, and were the average of at least three independent biological replicates $\left(n \geq 3\right.$, mean \pm SEM). The asterisk $\left.*^{*}\right)$ denotes a statistically significant difference $(p \leq 0.05)$ as calculated with the student's unpaired $t$-test 

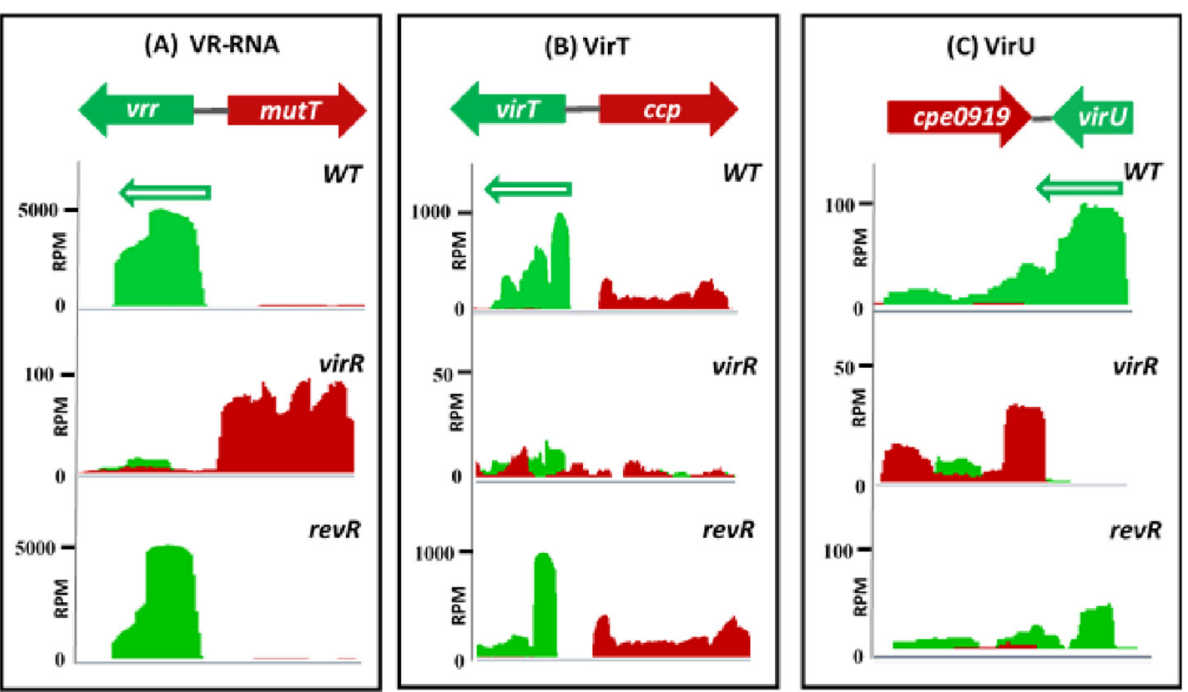

Fig. 6 Expression levels and depth of coverage plots of VR-RNA, VirT and VirU. Depth of coverage plots of a VR-RNA (cpe0957), b VirT (cpe0845) and $\mathbf{c}$ VirU (cpe0920) in the wild-type strain, and the virR and revR mutants are shown as visualized in Artemis. The genetic organization of each sRNA is shown on the top of each figure. Mapped RNA-seq data are displayed as a plot showing sequence depth for the forward (red) and reverse (green) strand. In the depth of coverage plots, the $Y$ axes represent the coverage depth in reads per million mapped reads (RPM). Expressed sRNAs are clearly seen as peaks in the depth of coverage plots

formation of a premature terminator during mid- to late- logarithmic growth phase.

The intergenic transcripts (SR1 to SR93) that were potentially regulated by VirR and RevR were also identified by performing comparative analysis of the RNA-seq data. In the virR mutant, only two sRNAs, SR45 and SR67, were up-regulated compared to the wild type, while in the revR mutant, four sRNAs, SR7, SR27, SR77 and SR82, were significantly downregulated (Table 2 \& Additional file 3: Table S3). These results indicated that in the wild-type strain the expression of SR45 and SR67 was usually repressed by VirR and that the expression of SR7, SR27, SR77 and SR82 was normally activated by RevR.

\section{Discussion}

In this study, we have used strand-specific RNA-seq to investigate the transcription of genes in a gas gangrenecausing isolate of $C$. perfringens. In particular, we analyzed gene expression in the virR and $\operatorname{rev} R$ regulatory mutants compared to the wild type. Through this analysis, we have identified a subset of genes that are regulated by both response regulators, but in a reciprocal manner. VirR was found to repress the expression of these genes, while RevR enhanced their expression. The proteins encoded by these genes can be classified into the extracellular enzymes, sporulation proteins and galactoside transporters functional groups. Both VirR and RevR may be independently repressing and enhancing the expression of these genes, respectively. Alternatively, the VirR and RevR regulatory systems may converge and confer opposite effects on one of their common secondary regulators, thereby leading to opposite outcomes on the expression of the target genes. The reciprocal regulation of genes has been described in Pseudomonas aeruginosa [40, 41], where multiple regulatory systems exert opposite effects on the expression of the sRNA RsmZ and therefore cause different downstream consequences to the RsmZ target genes [40].

Previous studies suggested that the VirR and RevR regulatory cascades were stimulated by different external signals. The signal that was proposed to activate the VirSR system is the AgrD-derived quorum sensing autoinducer peptide (AIP) $[17,18]$, while the RevR regulatory system was hypothesized to be triggered by inorganic phosphate levels [15]. Hence, reciprocal regulation of similar genes by VirR and RevR is unlikely to be the result of these systems responding differently to the same signal. Moreover, it is unlikely that the VirR and RevR pathways converge on the known sRNA molecules (VR-RNA, VirU and VirT) that are directly regulated by the VirSR regulatory system, since the RNA-seq results showed that the revR mutation had no effect on the expression of these sRNAs. Therefore, we postulate that VirR and RevR independently regulate these genes in a reciprocal manner.

The RNA-seq results provided evidence that VirR is a global negative regulator that represses the expression of 195 genes and enhances the expression of only 11 genes. It is not known how VirSR negatively regulates the expression of these genes, as no VirR boxes [20] were found in their promoter regions. Therefore, it is likely 


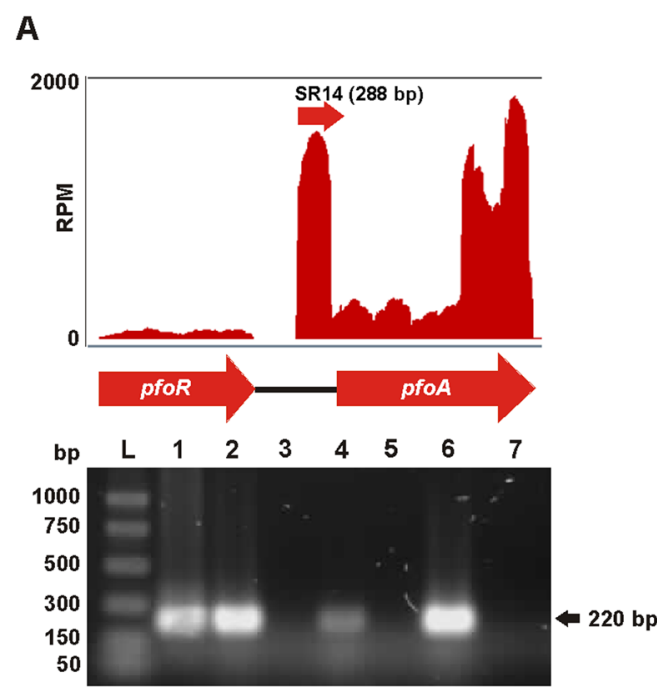

B

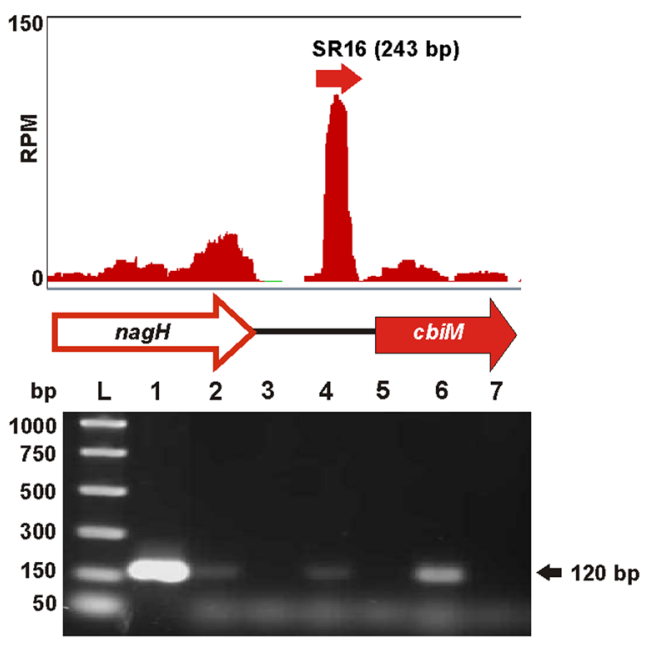

C

D
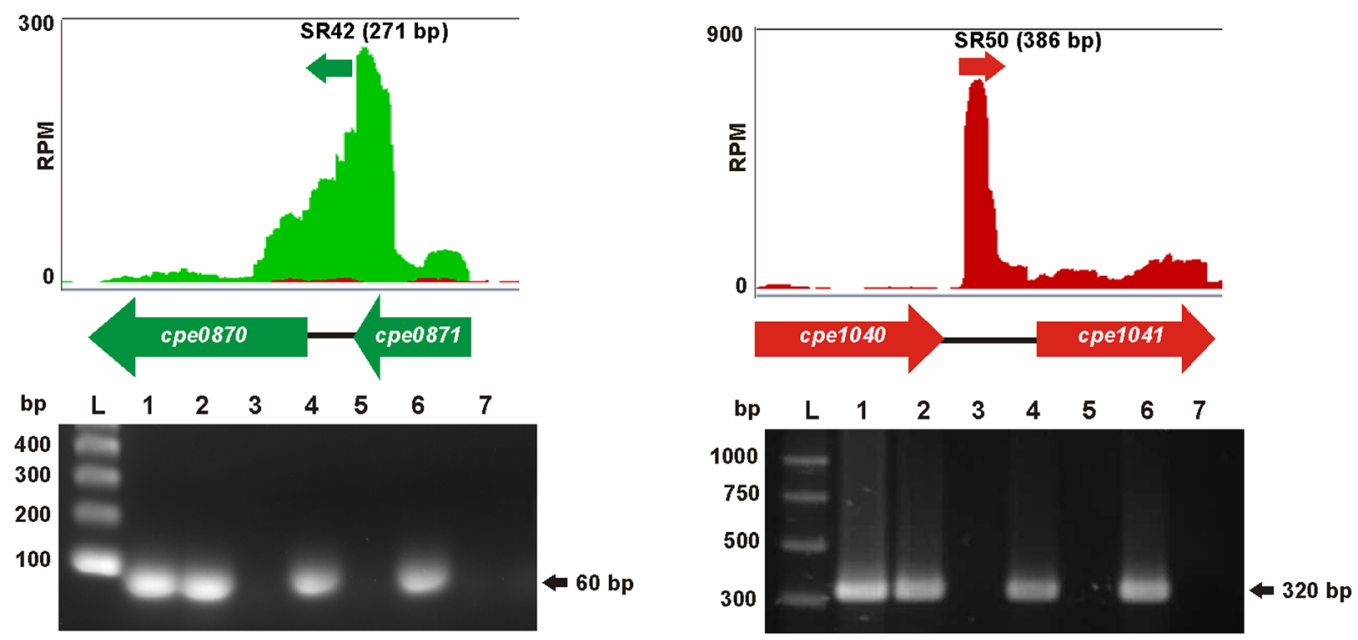

E
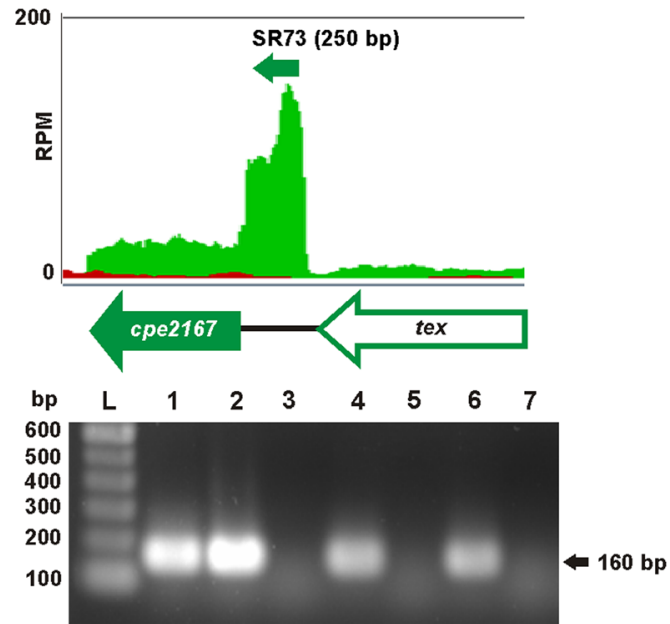

Fig. 7 (See legend on next page.) 


\section{(See figure on previous page.)}

Fig. 7 Validation of selected sRNA transcripts. Depth of coverage plots of a SR14, b SR16 c SR42, d SR50 and e SR73 together with their respective genetic organization and RT-PCR results are shown. Depth of coverage plots from the RNA-seq data of the wild-type JIR325 are depicted, where red and green graphs represent transcription on the sense- and antisense-strand, respectively. The $Y$ axes show the coverage depth in reads per million mapped reads (RPM) and the $X$ axes show the corresponding genetic organization. The approximate transcript lengths are indicated in brackets. Whole genes are represented by filled arrows, while open arrows indicate partial genes. RT-PCR was carried out to validate these unannotated transcripts. L, PCR marker ladder; 1, DNA control; 2, wild-type RNA with RT reaction; 3, wild-type RNA with no RT; 4, virR mutant RNA with RT; 5, virR mutant RNA with no RT; 6, revR mutant RNA with RT; 7, revR mutant RNA with no RT. The estimated sizes of the RT-PCR products (in $\mathrm{kb}$ ) are shown on the left of the agarose gel images

that negative regulation involves a secondary intermediate like VR-RNA, since it has previously been shown that the VirSR system regulates as many as 147 genes through this sRNA molecule [22]. Of the 11 genes that were positively regulated by VirR, five genes ( $p f o A, v r r$, virU, virT and $c c p$ ) were preceded by VirR boxes and thus were controlled directly by the binding of VirR to these sites $[19,20]$. This result is consistent with a previous microarray study [22]. The positive regulation of the cpe0094 gene by VirR was indirect and may be attributed to the VR-RNA molecule, as previously described [22]. How VirR positively regulates the remaining five genes (cpe0844, purE, cpe0947, fruA and pstC) is still unclear.

In a previous study, several virulence-associated genes were found to be under the positive control of the VirSR-VR-RNA cascade during the early- and midlogarithmic growth phase. The expression of genes including plc, colA, nagL, nanI, nanJ, nanE and nanA was affected by the $\operatorname{vrr}$ (VR-RNA) mutation [22]. By contrast, our RNA-seq results showed that the expression of $p l c$, colA, nanI, nanE and nanA was unchanged in the virR mutant, whereas nagL and nanJ were repressed by VirR at late-logarithmic growth phase. These contrasting results may have arisen because the vrr mutation has a more direct effect on the expression of its target genes compared to the mutation of virR, which encodes the positive regulator of vrr. An alternative explanation is that the RNA samples used in both transcriptomic studies were prepared from different media and growth phases. In addition, different analysis methods were employed in the two studies [22].

The transcriptomic results revealed that as many as 36 sporulation-related genes were negatively regulated by VirR (Additional file 2: Table S2). By contrast, four sporulation-associated genes were positively controlled by RevR (Additional file 3: Table S3). Similarly, previous microarray analysis indicated that expression of sporulation-related genes was affected by RevR [42]. Sporulation is a critical event in C. perfringens-mediated food poisoning. Resistant spores enhance the survival of the sporulating $C$. perfringens strains in the small intestine [43] and the enterotoxin (CPE) that is produced during sporulation has been shown to cause the symptoms of acute food poisoning [44, 45]. However, $C$. perfringens strain 13 is a CPE-negative gas gangrene strain that has a low sporulation efficiency [46]. It has been proposed that the absence of the spore coat proteins CotJB and CotJC, or the presence of a premature stop codon in the master sporulation regulatory gene spoOA, is responsible for the sporulation defect in this strain [36]. We have shown that the expression of sporulation genes was affected by the virR mutation, including genes encoding spore maturation proteins (SpoA/B), stage II to $\mathrm{V}$ proteins and sporulation sigma factors (SigF, SigG and SigK). The revR mutation also affected the expression of some sporulation-related genes, albeit to a lesser extent. Of these genes, $\operatorname{sig} F$ and $\operatorname{sig} G$ were significantly downregulated in the revR mutant, suggesting that these genes are normally activated by RevR. Note that the virR mutation has the opposite effect on these genes. These two sigma factors have been shown to be essential for sporulation, with SigF being critical for CPE production [43]. A VirR-independent sRNA, VirX, has also been reported to negatively regulate the expression of sporulation sigma factor genes, including sigE, sigF and sigK, and mutation of $\operatorname{vir} X$ leads to an increase in sporulation and CPE production in the food-poisoning strain SM101 [47]. The RNA-seq data showed that there was no significant difference in the expression of virX (cpe0646) in the virR mutant compared to the wild type. Hence, VirSR may work together with VirX to negatively regulate sporulation-related genes in sporulating C. perfringens strains.

The RNA-seq data showed that RevR behaves primarily as a positive regulator. The mechanism by which RevR regulates its target genes is as yet unknown. However, considering that it shares a high level of similarity with $\mathrm{PhoB}$, a response regulator in the phosphate $\left(\mathrm{P}_{\mathrm{i}}\right)$ signal transduction system, we previously postulated that RevR may function in a phosphate-dependent manner [15]. In E. coli, it has been suggested that the two-component proteins PhoR and PhoB sense phosphate levels by monitoring the activity of the phosphate-specific ATP-binding cassette transporter PstSCAB [48]. The RNA-seq results showed that genes (cpe0636 - cpe0641), which 


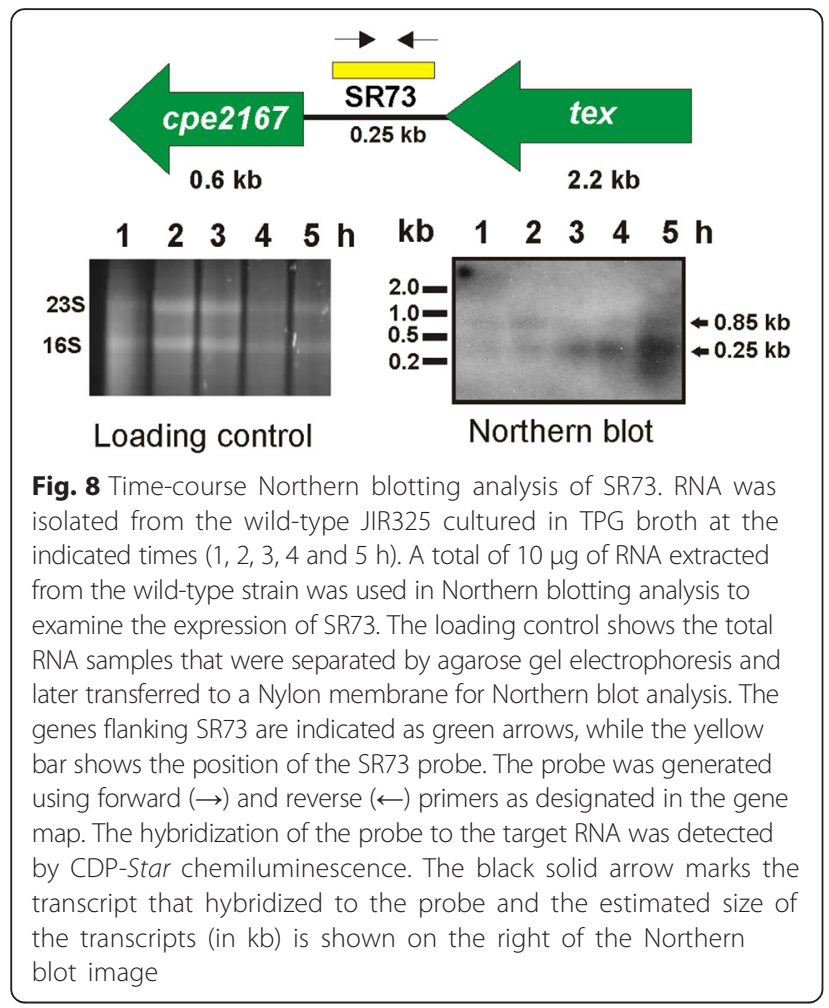

are located directly upstream of revR, and encode putative PstSCAB transporter proteins, were positively regulated by RevR.

These data indicate that RevR controls at least 44 genes independently of VirR. Consistent with previous findings, nagH, nanJ, nagL and cpe1753 (stage IV sporulation protein $\mathrm{A}$ ) were expressed at a lower level in the revR mutant [15]. Other genes, including nanI, $c c p$ and cpe0185, which were previously found to be expressed at a higher level in the revR mutant [15], showed no significant change in their expression levels in the current study. The expression of other genes also differed from that reported in a previous study [15]. The discrepancy may be due to different transcriptomic approaches, the use of different media and the fact that the RNA was isolated at different time points.
KEGG and GO analysis of the differentially expressed genes in both mutants revealed the potential physiological roles of the VirSR and RevR regulatory systems. However, further experiments need to be conducted to substantiate the proposed functions of these candidate genes and any potential roles in virulence. Half of the GO overrepresented categories in the virR mutant were involved in cell developmental processes that lead to changes in the cell over time, indicating that the VirSR regulatory system not only has a role in virulence, but also influences the growth of $C$. perfringens. In the revR mutant, other than the phosphate transmembrane transporter system, cell membrane proteins and transporters were significantly over-represented in the differentially regulated genes, suggesting that RevR may have a major role in maintaining membrane integrity and controlling the uptake and/or export of nutrient/ions in C. perfringens.

VirSR is one of the most important regulatory systems in C. perfringens and this regulon has been characterized using different approaches [21, 22, 49, 50]. However, none of these studies addressed the transcripts within intergenic regions or on pCP13, except for one study, which provided preliminary evidence that the VirSR system affects the expression of the $c n a B$ and $c p b 2$ genes on pCP13 [37]. Microarray analysis failed to detect transcription of other pCP13 genes [22], probably due to the low expression levels of transcripts from these regions and the narrow dynamic range of the microarray technique. In this study, comparative RNA-seq analysis showed that both VirR and RevR alter the transcription of pCP13 genes, with VirR having a more noticeable effect. The expression of 47 pCP13 genes was at least four times lower in the virR mutant compared to the wild-type strain. It is possible that some of these changes may be due to indirect effects of the response regulator(s) on plasmid copy number. Previously, the $c n a B$ and $c p b 2$ genes were found to be negatively and positively regulated, respectively, by the VirSR system in a VR-RNA dependent manner during the mid to late logarithmic growth phases [37]. However, the results obtained in this study indicated that both genes were positively regulated by the VirSR regulatory system during late logarithmic growth phase and have provided

Table 2 Differentially expressed sRNAs in the virR and revR mutants

\begin{tabular}{lllllll}
\hline Strain & SRNA & Gene 1 & Product 1 a,b & Gene 2 & Product 2,b & $\log _{2}$ fold change \\
\hline virR mutant & SR45 & eutQ & entanolamine utilization protein & btuE & glutathione peroxidase & 2.19 \\
& SR67 & valS & valine-tRNA ligase & cpe1920 & hypothetical protein & 1.85 \\
revR mutant & SR7 & mviM & dehydrogenase & nirC & nitrite transporter & -3.74 \\
& SR27 & cpe0454 & membrane protein & cpe0455 & alkaline phosphatase-like protein & -2.54 \\
& SR77 & ddpA & oligopeptide transporter & nark & nitrate extrusion protein & -2.62 \\
& SR82 & bglB & beta-glucosidase & putA & aldehyde dehydrogenase & -1.97 \\
\hline
\end{tabular}

${ }^{\mathrm{a}}$ As defined by FDR $<0.01 ; \log _{2}$ fold change $>1$

${ }^{\mathrm{b}}$ Gene 1 and gene 2 are used to designate the genes on each side on the postulated sRNA gene 
evidence that the VirR and RevR regulatory systems control not only chromosomally-encoded genes, but also the expression of plasmid-encoded genes.

It is now well established that sRNAs regulate diverse processes in bacteria, ranging from stress adaptation to the control of central and secondary metabolism and virulence processes [31, 51]. By employing strandspecific RNA-seq, we have identified 93 novel transcripts encoded on the wild-type chromosome (Additional file 7: Table S6). Of these previously unannotated transcripts, 30 corresponded to previous in silico-predicted sRNAs of C. perfringens strain 13 [52] (Additional file 7: Table S6), strongly supporting their approach. Comparative analysis of the expression of these sRNAs in the wild type and the mutants revealed that VirSR and RevR regulated the expression of two and four sRNAs, respectively (Table 2). Note that although RNA-seq depth of coverage plots can provide a preview of the transcription pattern, which helps in the prediction of putative sRNAs, Northern blots need to be conducted to confirm whether these putative sRNAs are independent molecules or read-through transcripts from close adjacent genes. Our studies have laid the foundation for further analysis of the sRNAs of C. perfringens. The primary remaining challenge is to decipher the functional roles of these putative sRNAs. These studies will identify new regulatory systems, and will likely extend many established signaling pathways. For example, a potential sRNA, SR14, was identified upstream of the $p f o A$ gene (Fig. 7a). Sequence analysis of the potential coding region of SR14 showed that this putative sRNA was located downstream of the VirR binding sites, the VirR boxes, and the $p f o A$ promoter. Although there is no experimental evidence to show that SR14 affects the expression of $p f o A$, the potential involvement of a sRNA would suggest that the regulation of PFO production may be much more complex than previously thought. Irrespective of the outcome of such studies, the identification of these novel transcripts has greatly refined the annotation of the $C$. perfringens genome, aiding to the current knowledge of this important pathogenic bacterium.

\section{Conclusions}

In summary, in this study RNA-seq was used to analyze the transcriptional activity of $C$. perfringens strain JIR325 and its isogenic virR and revR mutants. The VirR and RevR regulons include chromosomally encoded genes, pCP13-encoded genes and previously unidentified sRNAs. VirR was found to behave primarily as a global negative regulator, while RevR acted as a global positive regulator. Furthermore, our data indicate that a small subset of genes are regulated by both the VirSR and RevR pathways. Further investigation is needed to answer many questions arising from this study, such as the relative importance of the VirR and RevR pathways and the functional roles of the novel sRNA transcripts. Nevertheless, the results reported in this study have significantly enhanced our understanding of these virulence-related regulatory systems.

\section{Additional files}

\section{Additional file 1: Table S1. Oligonucleotide primers used in this study} (DOCX $14 \mathrm{~kb}$ )

Additional file 2: Table S2. Genes with significant change in expression between the wild type and virR mutant as identified by the edgeR analysis package. (DOCX $29 \mathrm{~kb}$ )

Additional file 3: Table S3. Genes with significant change in expression between the wild type and revR mutant as identified by the edgeR analysis package. (DOCX $18 \mathrm{~kb}$ )

Additional file 4: Figure S1. Validation of replicate RNA-seq data (TIF $242 \mathrm{~kb})$

Additional file 5: Table S4. Plasmid pCP13 genes that are differentially expressed in the virR mutant compared to the wild type. (DOCX $15 \mathrm{~kb}$ )

Additional file 6: Table S5. Plasmid pCP13 genes that are differentially expressed in the revR mutant compared to the wild type. (DOCX $13 \mathrm{~kb}$ )

Additional file 7: Table S6. Small RNAs identified from the wild-type depth of coverage plot. (DOCX $17 \mathrm{~kb})$

\section{Competing interests}

The authors declare that they have no competing interests.

\section{Author's contributions}

Experiments were conceived and designed by L-YL, JKC and JIR. Experiments were carried out by $L-Y L$. RNA-seq data were analysed by $P F H$ and $L-Y L$. The manuscript was prepared by L-YL, JKC and JIR. JDB and $Y-H L$ made a critical revision of the manuscript and participated in helpful discussions. All authors read and approved the final manuscript.

\section{Acknowledgements}

These studies were supported by project grants GNT1065985 and GNT1082401 from the Australian National Health and Medical Research Council. Lee-Yean Low was the recipient of a Monash Postgraduate Scholarship. We thank Dr Kaori Ohtani (Kanazawa University, Japan) for helpful advice with the Northern blot analysis and Associate Professor David Powell (Monash University) for help with RNA-seq analysis.

\section{Author details}

${ }^{1}$ Infection and Immunity Program, Biomedicine Discovery Institute and Department of Microbiology, Monash University, Clayton 3800, Australia. ${ }^{2}$ Monash Bioinformatics Platform, Monash University, Clayton 3800, Australia.

Received: 9 February 2016 Accepted: 5 May 2016

Published online: 23 May 2016

\section{References}

1. Rood Jl, Cole ST. Molecular genetics and pathogenesis of Clostridium perfringens. Microbiol Rev. 1991;55:621-48.

2. Rood JI. Virulence genes of Clostridium perfringens. Annu Rev Microbiol. 1998;52:333-60.

3. Songer JG. Clostridia as agents of zoonotic disease. Vet Microbiol. 2010; 140(3-4):399-404

4. Li J, Adams V, Bannam TL, Miyamoto K, Garcia JP, Uzal FA, Rood Jl, McClane BA. Toxin plasmids of Clostridium perfringens. Microbiol Mol Biol Rev. 2013;77(2):208-33.

5. Titball R, Rood J. Bacterial phospholipases. In: Bacterial protein toxins. Aktories K, Just I, editors. Berlin Heidelberg: Springer-Verlag; 2000. p. 529-56.

6. Revitt-Mills SA, Adams VM, Rood Jl. Clostridium perfringens extracellular toxins and enzymes: 20 and counting. Microbiology Australia. 2015;36(3):114-7. 
7. Awad MM, Bryant AE, Stevens DL, Rood Jl. Virulence studies on chromosomal a-toxin and $\theta$-toxin mutants constructed by allelic exchange provide genetic evidence for the essential role of a-toxin in Clostridium perfringens-mediated gas gangrene. Mol Microbiol. 1995;15:191-202.

8. Awad MM, Ellemor DM, Boyd RL, Emmins JJ, Rood Jl. Synergistic effects of a-toxin and perfringolysin $\mathrm{O}$ in Clostridium perfringens-mediated gas gangrene. Infect Immun. 2001;69:7904-10.

9. Flores-Diaz M, Alape-Giron A, Clark G, Catimel B, Hirabayashi Y, Nice E, Gutierrez JM, Titball R, Thelestam M. A cellular deficiency of gangliosides causes hypersensitivity to Clostridium perfringens phospholipase C. J Biol Chem. 2005;280(29):26680-9.

10. Matsushita O, Okabe A. Clostridial hydrolytic enzymes degrading extracellular components. Toxicon. 2001;39(11):1769-80.

11. Chiarezza M, Lyras D, Pidot SJ, Flores-Diaz M, Awad MM, Kennedy CL, Cordner LM, Phumoonna T, Poon R, Hughes ML et al. The Nanl and NanJ sialidases of Clostridium perfringens are not essential for virulence. Infect Immun. 2009:77(10):4421-8.

12. Lyristis M, Bryant AE, Sloan J, Awad MM, Nisbet IT, Stevens DL, Rood JI. Identification and molecular analysis of a locus that regulates extracellular toxin production in Clostridium perfringens. Mol Microbiol. 1994;12:761-77.

13. Shimizu T, Yaguchi H, Ohtani K, Banu S, Hayashi H. Clostridial VirR/VirS regulon involves a regulatory RNA molecule for expression of toxins. Mol Microbiol. 2002;43(1):257-65.

14. Ohtani K, Bhowmik SK, Hayashi H, Shimizu T. Identification of a novel locus that regulates expression of toxin genes in Clostridium perfringens. FEMS Microbiol Lett. 2002;209(1):113-8.

15. Hiscox TJ, Chakravorty A, Choo JM, Ohtani K, Shimizu T, Cheung JK, Rood Jl. Regulation of virulence by the RevR response regulator in Clostridium perfringens. Infect Immun. 2011:79(6);2145-53.

16. Shimizu T, Ba-Thein W, Tamaki M, Hayashi $H$. The virR gene, a member of class of two-component response regulators, regulates the production of perfringolysin $\mathrm{O}$, collagenase, and hemagglutinin in Clostridium perfringens. J Bacteriol. 1994;176:1616-23.

17. Ohtani K, Yuan Y, Hassan S, Wang R, Wang Y, Shimizu T. Virulence gene regulation by the agr system in Clostridium perfringens. J Bacteriol. 2009; 191(12):3919-27.

18. Vidal JE, Ma M, Saputo J, Garcia J, Uzal FA, McClane BA. Evidence that the Agr-like quorum sensing system regulates the toxin production, cytotoxicity and pathogenicity of Clostridium perfringens type C isolate CN3685. Mol Microbiol. 2012;83(1):179-94.

19. Cheung JK, Rood JI. The VirR response regulator from Clostridium perfringens binds independently to two imperfect direct repeats located upstream of the $p f o A$ promoter. J Bacteriol. 2000;182:57-66.

20. Cheung JK, Dupuy B, Deveson DS, Rood JI. The spatial organization of the VirR boxes is critical for VirR-mediated expression of the perfringolysin 0 gene, pfoA, from Clostridium perfringens. J Bacteriol. 2004;186(11):3321-30.

21. Okumura K, Ohtani K, Hayashi H, Shimizu T. Characterization of genes regulated directly by the VirR/VirS system in Clostridium perfringens. J Bacteriol. 2008;190(23):7719-27.

22. Ohtani K, Hirakawa H, Tashiro K, Yoshizawa S, Kuhara S, Shimizu T. Identification of a two-component VirR/VirS regulon in Clostridium perfringens. Anaerobe. 2010;16(3):258-64.

23. Wade B, Keyburn AL, Seemann T, Rood JI, Moore RJ. Binding of Clostridium perfringens to collagen correlates with the ability to cause necrotic enteritis in chickens. Vet Microbiol. 2015;180(3-4):299-303.

24. Cheung JK, Keyburn AL, Carter GP, Lanckriet AL, Van Immerseel F, Moore RJ, Rood JI. The VirSR two-component signal transduction system regulates NetB toxin production in Clostridium perfringens. Infect. Immun. 2010;78(7): 3064-72.

25. Parkhomchuk D, Borodina T, Amstislavskiy V, Banaru M, Hallen L, Krobitsch S, Lehrach $\mathrm{H}$, Soldatov A. Transcriptome analysis by strand-specific sequencing of complementary DNA. Nucleic Acids Res. 2009:37(18), e123.

26. Rutherford K, Parkhill J, Crook J, Horsnell T, Rice P, Rajandream MA, Barrell B. Artemis: sequence visualisation and annotation. Bioinformatics. 2000;16:944-5.

27. Robinson MD, McCarthy DJ, Smyth GK. edgeR: a Bioconductor package for differential expression analysis of digital gene expression data. Bioinformatics (Oxford, England). 2010;26(1):139-40.

28. Marx W. Spearman's Rho: a "false" rank correlation? Arch Psychol (Frankf) 1981;134(2):161-4

29. Young MD, Wakefield MJ, Smyth GK, Oshlack A. Gene ontology analysis for RNA-seq: accounting for selection bias. Genome Biol. 2010;11(2):R14
30. Romilly C, Caldelari I, Parmentier D, Lioliou E, Romby P, Fechter P. Current knowledge on regulatory RNAs and their machineries in Staphylococcus aureus. RNA Biol. 2012;9(4):402-13.

31. Weissenmayer BA, Prendergast JG, Lohan AJ, Loftus BJ. Sequencing illustrates the transcriptional response of Legionella pneumophila during infection and identifies seventy novel small non-coding RNAs. PLoS One. 2011;6(3), e17570.

32. Kobayashi T, Shimizu T, Hayashi H. Transcriptional analysis of the betagalactosidase gene $(p b g)$ in Clostridium perfringens. FEMS Microbiol Lett. 1995;133(1-2):65-9.

33. Ba-Thein W, Lyristis M, Ohtani K, Nisbet IT, Hayashi H, Rood Jl, Shimizu T. The virR/virS locus regulates the transcription of genes encoding extracellular toxin production in Clostridium perfringens. J Bacteriol. 1996;178(9):2514-20.

34. Ashburner M, Ball CA, Blake JA, Botstein D, Butler H, Cherry JM, Davis AP, Dolinski K, Dwight SS, Eppig JT et al. Gene ontology: tool for the unification of biology. The Gene Ontology Consortium. Nat Genet. 2000;25(1):25-9.

35. Kanehisa M, Goto S. KEGG: kyoto encyclopedia of genes and genomes. Nucleic Acids Res. 2000;28(1):27-30

36. Shimizu T, Ohtani K, Hirakawa H, Ohshima K, Yamashita A, Shiba T, Ogasawara N, Hattori M, Kuhara S, Hayashi H. Complete genome sequence of Clostridium perfringens, an anaerobic flesh-eater. Proc Natl Acad Sci U S A. 2002:99:996-1001

37. Ohtani K, Kawsar HI, Okumura K, Hayashi H, Shimizu T. The VirR/VirS regulatory cascade affects transcription of plasmid-encoded putative virulence genes in Clostridium perfringens strain 13. FEMS Microbiol Lett. 2003:222(1):137-41.

38. Banu S, Ohtani K, Yaguchi H, Swe T, Cole ST, Hayashi H, Shimizu T. Identification of novel VirR/VirS-regulated genes in Clostridium perfringens. Mol Microbiol. 2000;35:854-64.

39. Breaker RR Riboswitches and the RNA world. Cold Spring Harb Perspect Biol. 2012:4(2):a003566

40. Ventre I, Goodman AL, Vallet-Gely I, Vasseur P, Soscia C, Molin S, Bleves S, Lazdunski A, Lory S, Filloux A. Multiple sensors control reciprocal expression of Pseudomonas aeruginosa regulatory RNA and virulence genes. Proc Natl Acad Sci U S A. 2006;103(1):171-6.

41. Goodman AL, Kulasekara B, Rietsch A, Boyd D, Smith RS, Lory S. A signaling network reciprocally regulates genes associated with acute infection and chronic persistence in Pseudomonas aeruginosa. Dev Cell. 2004;7(5):745-54.

42. Chakravorty A, Awad MM, Hiscox TJ, Cheung JK, Carter GP, Choo JM, Lyras $\mathrm{D}$, Rood Jl. The cysteine protease alpha-clostripain is not essential for the pathogenesis of Clostridium perfringens-mediated myonecrosis. PLoS One. 2011;6(7), e22762.

43. Li J, McClane BA. Evaluating the involvement of alternative sigma factors SigF and SigG in Clostridium perfringens sporulation and enterotoxin synthesis. Infect Immun. 2010;78(10):4286-93.

44. Sarker MR, Carman RJ, McClane BA. Inactivation of the gene (cpe) encoding Clostridium perfringens enterotoxin eliminates the ability of two cpe-positive C. perfringens type A human gastrointestinal disease isolates to affect rabbit ileal loops. Mol Microbiol. 1999;33(5):946-58.

45. Fernandez Miyakawa ME, Pistone Creydt V, Uzal FA, McClane BA, Ibarra C. Clostridium perfringens enterotoxin damages the human intestine in vitro. Infect Immun. 2005;73(12):8407-10.

46. Myers GS, Rasko DA, Cheung JK, Ravel J, Seshadri R, DeBoy RT, Ren Q, Varga J, Awad MM, Brinkac LM et al. Skewed genomic variability in strains of the toxigenic bacterial pathogen. Clostridium perfringens. Genome Res. 2006; 16(8):1031-40

47. Ohtani K, Hirakawa H, Paredes-Sabja D, Tashiro K, Kuhara S, Sarker MR, Shimizu T. Unique regulatory mechanism of sporulation and enterotoxin production in Clostridium perfringens. J Bacteriol. 2013;195(12):2931-6.

48. Peterson CN, Mandel MJ, Silhavy TJ. Escherichia coli starvation diets: essential nutrients weigh in distinctly. J Bacteriol. 2005;187(22):7549-53.

49. Frandi A, Mengoni A, Brilli M. Comparative genomics of VirR regulons in Clostridium perfringens strains. BMC Microbiol. 10:65;1471-2180.

50. Shimizu T, Shima K, Yoshino K, Yonezawa K, Hayashi H. Proteome and transcriptome analysis of the virulence genes regulated by the VirR/VirS system in Clostridium perfringens. J Bacteriol. 2002;184(10):2587-94.

51. Caldelari I, Chao Y, Romby P, Vogel J. RNA-mediated regulation in pathogenic bacteria. Cold Spring Harb Perspect Med. 2013;3(9):a010298.

52. Chen Y, Indurthi DC, Jones SW, Papoutsakis ET. Small RNAs in the Genus Clostridium. MBio, 2011:2(1):e00340-10. 